\title{
Performance Comparison of Cryogenic Treated Tool Vs Untreated Tool using an Accelerometer Sensor
}

\author{
D.Murali, K.Narayanamoorthy, N.Aagashram, Rehan Baig, K.Gnanasekaran, K.Ramesh
}

\begin{abstract}
In this paper, performance of the Cryogenic treated tool along with the untreated tool is investigated in turning of En8 Medium carbon steel. Results are got by comparing parameters of vibration in tool. For vibration Accelerometer sensor, it is used to find the Acceleration of tool in $X, Y$ and $Z$ axis for incremental depth of cut. The cryogenic tool has lesser machining time, increased tool life and surface finish due to the reduced vibration than the untreated tool.
\end{abstract}

Keywords: Cryogenic, Treated Tool, Accelerometer, Vibration

\section{INTRODUCTION}

The rise of modern material has paved the way for the increase in the use of Unconventional Machining Process due to the high hardness and strength of the materials they are dealing with. Even though, majority of the Ferrous based alloys, Polymers and same composites are machined by Conventional machines such as Lathe, Milling, etc., which uses Physical contact-based cutting tool. The tool hardness is important which must be higher than that of the workpiece to remove the material. Increasing the hardness must be economical with enough cost benefits. The use of Cryogenic Treated tool increase hardness without heat treatment, which the future adds to environmental benefits. R. Dhar et al [1] conducted a performance evaluation on uncoated tungsten carbide tool with AISI 1040 steel at low temperature. In this work, the feed rate, cutting speed is the varying parameters. Depth of cut is maintained constant. Finally, the results display the cutting force during the machining process is reduced at the same time tool interface temperature and surface roughness is reduced. $\mathrm{H}$. Chelladurai et al [2] researched the monitoring condition system to improve the cutting tool wear with influences the quality of the machined surface. The variable parameters are cutting speed, feed rate, depth of cut and flank wear, is machined under an electrical

Revised Manuscript Received on November 25, 2020.

* Correspondence Author

D. Murali*, Assistant Professor St. Joseph's Institute of Technology, Chennai

K. Narayanamoorthy, Assistant Professor St. Joseph's Institute of Technology, Chennai

Aagashram Neelakandan, B.E Mechanical Engineering inSt. Joseph's Institute of Technology

Rehan Biag, B.E Mechanical Engineering in St. Joseph's Institute of Technology

K. Gnanasekaran, Assistant Professor in St. Joseph's Institute of Technology, Chennai

Ramesh Krishnan, Assistant Professor in St. Joseph's Institute of Technology, Chennai

(C) The Authors. Published by Blue Eyes Intelligence Engineering and Sciences Publication (BEIESP). This is an open access article under the CC BY-NC-ND license (http://creativecommons.org/licenses/by-nc-nd/4.0/) discharge machining. They utilize the neural network as an optimization process which directly influence the dynamic characteristics of the machining process they results conclude that artificial wear is controlled. Vibration during machining process helps to predict the flank wear. Joseph c, Chen et al [3] researched tool breakage detection using accelerometer sensor which helps to sense the breakage with feed rate, depth of cut and speed as the influencing parameters.

\section{EXPERIMENT AND SETUP}

Cutting experiments were conducted in Lathe under dry cooling condition. Both treated and untreated tool is used to cut En8. For Vibration analysis, the Accelerometer sensor MPU-6050 is connected with the Microcontroller ATMega328 in an Arduino Nano Development Board. From the Arduino to record the data, we used Microsoft Excel for automatic recording and updating of the value as the Machining is done. The Cutting Performance Test is conducted for En8 sample. The tools are mounted on the tool holder on the lathe with Accelerometer attached to the side of the tool. The specimen En8 has the diameter of $25 \mathrm{~mm}$ and length of $150 \mathrm{~mm}$ with $50 \mathrm{~mm}$ for holding the workpiece. The Length provided for holding the workpiece which 1/3rd of the total length because it increases the stiffness of the Workpiece in the chuck to prevent external noises in the measurement of vibration. The accelerometer is first calibrated and then the test begins. The turning operation is done starting from the depth of cut of $0.1 \mathrm{~mm}$ for the full-length cut and the depth of cut is increased to $0.2 \mathrm{~mm}$ and so on. The lathe is set to an automatic feed of $0.2 \mathrm{~m} / \mathrm{min}$ and the spindle speed is set to 1200rpm to reduce any error. For all the turning operation of both treated and untreated, the vibration data along with timestamp is recorded from the sensor using Excel. The turning operations are performed on the same material for different depth of cuts with the same feed rate and cutting speed.

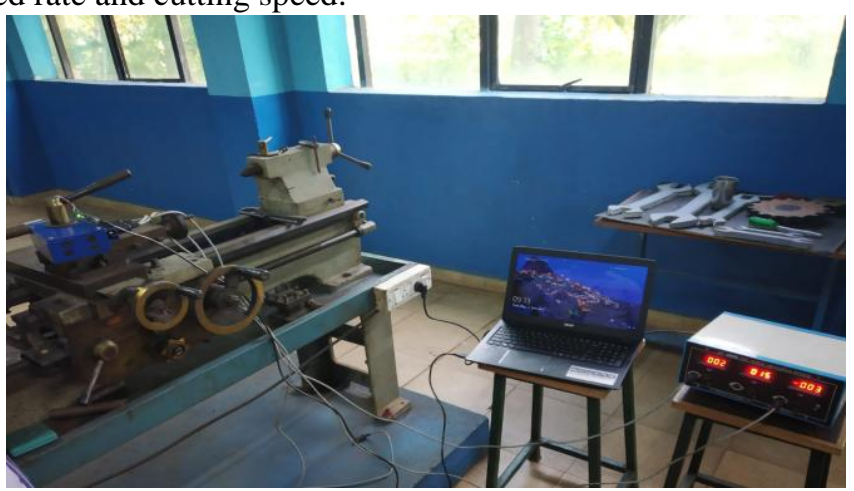

Fig. 1. Experimental Setup

Published By:

Blue Eyes Intelligence Engineering and Sciences Publication

(C) Copyright: All rights reserved.

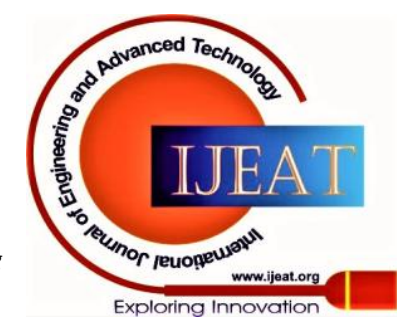




\section{Performance Comparison of Cryogenic Treated Tool Vs Untreated Tool using an Accelerometer Sensor}

\section{RESULT AND DISCUSSION}

The data got from the Accelerometer Sensor consists of acceleration of the tool in $\mathrm{X} Y$ and $\mathrm{Z}$ axis. For each Depth of cut, Acceleration values in X-Axis, Y-Axis and Z-Axis are plotted for their corresponding.
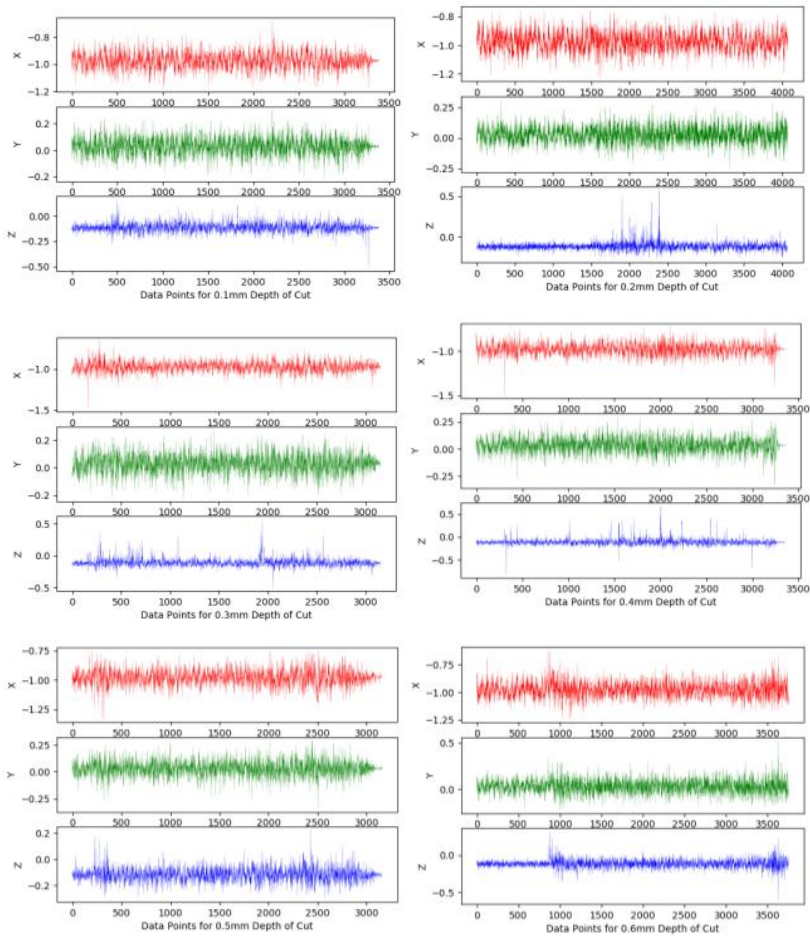

Fig. 1. Plots of Acceleration values in $X, Y$ and $Z$ axis of Treated Tool for depth of cuts $0.1 \mathrm{~mm}$ to $0.6 \mathrm{~mm}$
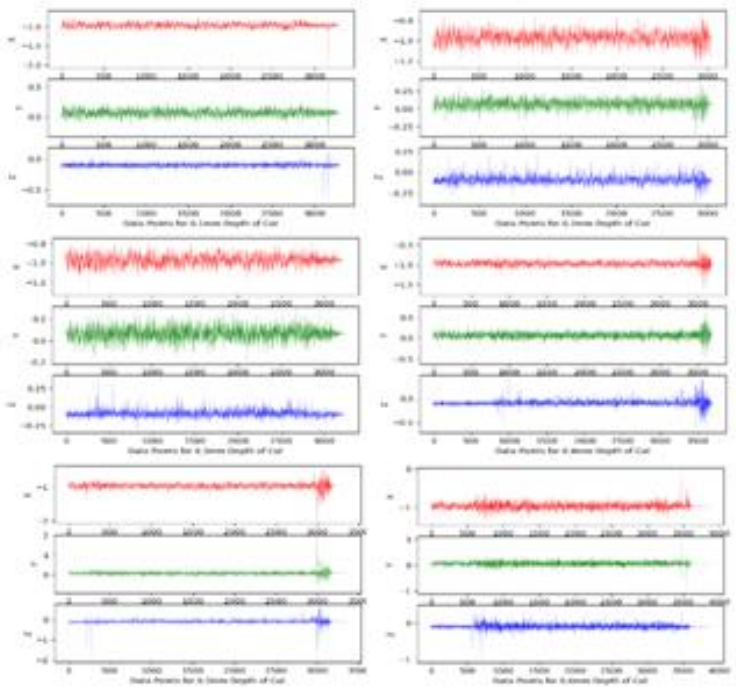

Fig. 2. Plots of Acceleration values in $\mathrm{X}, \mathrm{Y}$ and $\mathrm{Z}$ axis of Untreated Tool for depth of cuts $0.1 \mathrm{~mm}$ to $0.6 \mathrm{~mm}$

From the Acceleration value to make sense we are taking the average of the acceleration value in each axis for different depth of cut. The graph is made by taking the depth of cut on $\mathrm{X}$-Axis and Acceleration in Y-Axis and it is compared with both treated and untreated tool.

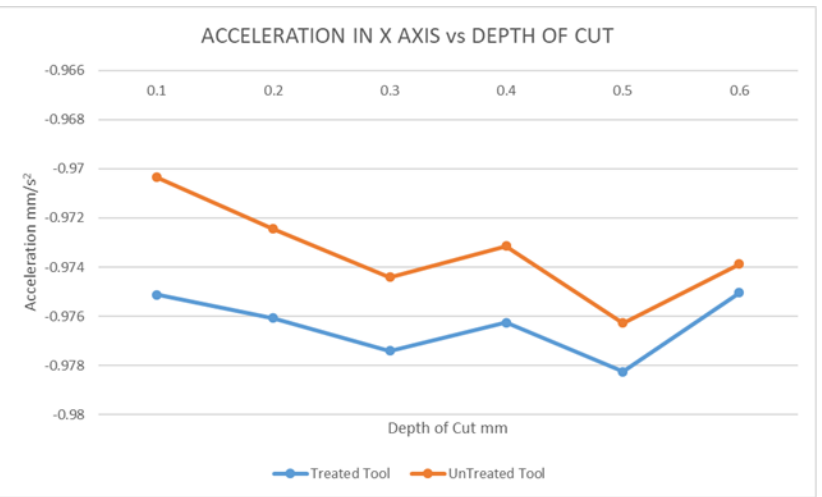

Fig. 3.Comparison of Depth of cut with Acceleration data on $\mathrm{X}$-Axis

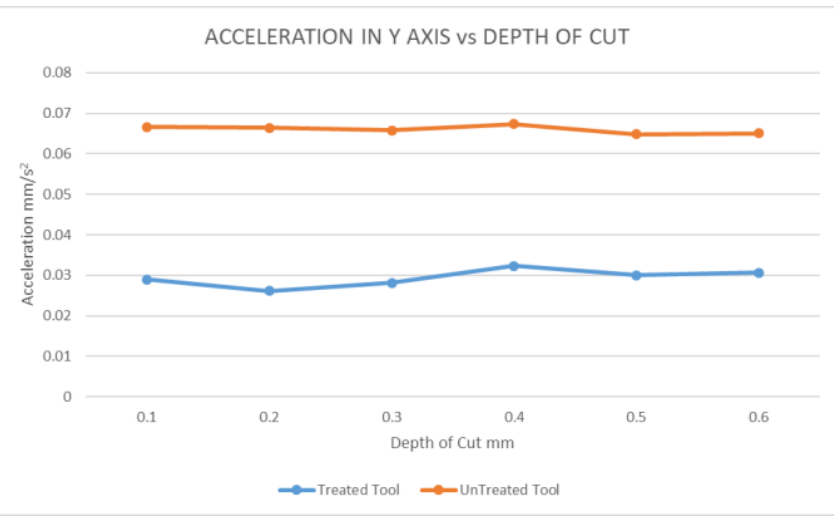

Fig. 4.Comparison of Depth of cut with Acceleration data on Y-Axis

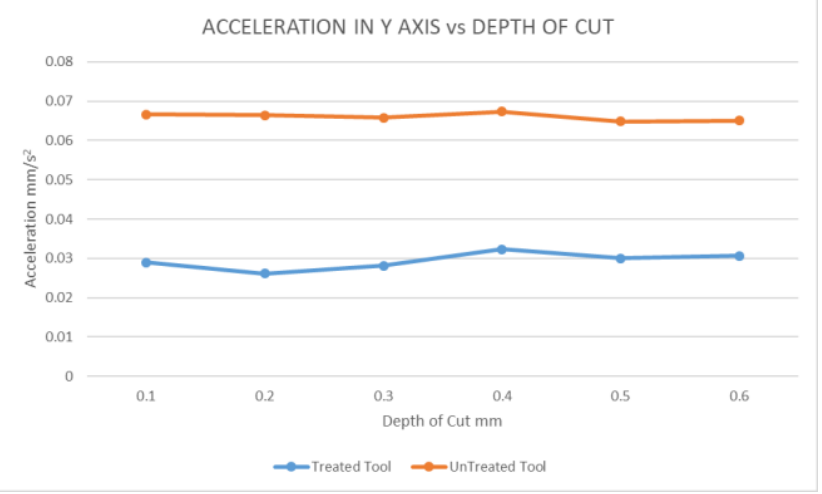

Fig. 5.Comparison of Depth of cut with Acceleration data on Z-Axis

\section{CONCLUSION}

From the data we get to conclude the following results,

1. From the plots, we can conclude that the vibration of treated tool is less than the untreated tool.

2. So that the Cryogenic Treatment increase the life of tool.

3. It improves the surface finish of the Work piece as it absorbs more vibration and gives more uniform motion.

4. Wear is also reduced due to reduction in unwanted motion.

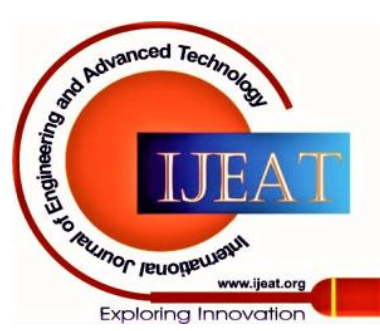




\section{REFERENCES}

1. W.-K. Chen1N. R. Dhar and A. K. M. Masud "Performance Evaluation Of Uncoated Tungsten Carbidetool In Turning Aisi 1040 Steel At Low Temperature" ICME 2001, Dhaka, December 26-28

2. H. Chelladurai\& V. K. Jain \& N. S. Vyas "Development of a cutting tool condition monitoring systemfor high speed turning operation by vibrationand strain analysis" Int J Adv Manuf Technol (2008) 37:471-485

3. 3 JOSEPH C. CHEN1* and WEI-LIANG CHEN "A tool breakage detection system usingan accelerometer sensor" Journal of Intelligent Manufacturing (1999) 10, 187 \pm 197

4. Vasa Ramu,Nishok Sriram .S.R,P.Hani Deep“Carbon Steel EN8 and EN 19 Tool Wear Reduction by Cryogenic Treatment” IJETSR ISSN 2394 3386 Volume 4, Issue 5 May (2017)

5. Flavio J. da Silva a, Sine'sio D. Franco b,*, A` lisson R. Machado c, Emmanuel O. Ezugwu d.

6. Ant"onio M. Souza Jr. e "Performance of cryogenically treated HSS tools" Wear 261 (2006) 674-685

7. J.D. Kamody, Using deep cryogenics to advantage, Adv. Mater. Process.10 (1998) 215-218.[29] P. Wright, E.M. Trent.

8. Alexandru, G. Ailincai, C. Baciu, Influence de traitementsthermiques `abassetemp'eature sur la dur'ee de vie des aciers `a outils `a coupe reapidetr`es.

9. M'emoires et etudes scientifiques revue de Metallurgie (1990) 283-388 (inFrench).

\section{AUTHORS PROFILE}

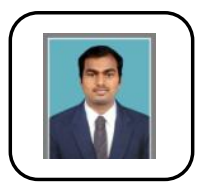

D. Murali has completed his Bachelor of Engineering degree in the year of 2010 from RMK Engineering College, Chennai and his Master Degree in the year of 2016 from St. Joseph's College of Engineering. Now he is working as an Assistant Professor in St. Joseph's Institute of Technology, Chennai. He is a Life time Membership in Indian Society for Technical Education. He has published 2 research paper in international journal.

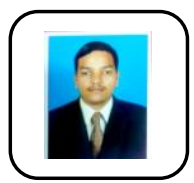

K. Narayanamoorth yhascompletedhis B.E Mechanical Engineering in the year of 2010 from R.M.K Engineering College and his $\mathbf{M}$ Tech is in the year of 2016 from AC College of Technology campus Anna University in Industrial Safety and Hazards Management.Now he is working as an Assistant Professor in St. Joseph's Institute of Technology, Chennai.He is a Life time Membership in Indian Society for Technical Education. He has published 2 research paper in international journal.

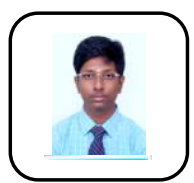

Aagashram Neelakandan is in Final Year of his B.E Mechanical Engineering inSt. Joseph's Institute of Technology. He is student member in IEI, ISHRAE and SAE.

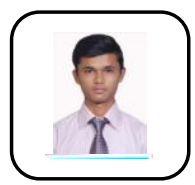

Rehan Biagis in Final Year of his B.E Mechanical Engineering in St. Joseph's Institute of Technology. He is student member in IEI, ISHRAE. Completed one Funded Project from ISHRAE and Awarded Best Student by IEI Local Chapter Kanchipuram.

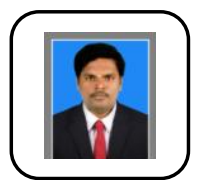

K. Gnanasekaran has completed his Bachelor of Engineering degree in the year of 2015 from Dhanalakshmi Srinivasan College of Engineering and Technology, Chennai and his Master Degree in the year of 2017 from St. Joseph's College of Engineering, Chennai. Now he is working as an Assistant Professor in St. Joseph's Institute of Technology, Chennai. He is a Life time Membership in Indian Society for Technical Education. He has published 3 research paper in international journal.

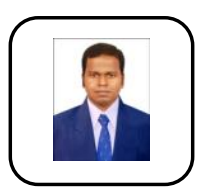

Ramesh Krishnan has finished his Bachelor of Engineering degree in the year of 2008 from C. Abdul Hakeem College of Engineering and Technology, Vellore and his Master Degree in the year of 2012 from College of Engineering, Guindy. Now he is working as an Assistant Professor in St. Joseph's Institute of

Published By:

Blue Eyes Intelligence Engineering and Sciences Publication (C) Copyright: All rights reserved.
Technology, Chennai. He is a Life time Membership in Indian Society for Technical Education. He has published 3 research paper in international journal. 